\title{
4
}

\section{Dramatic Monologue in Crisis: Agency and Exchange in D. G. Rossetti's "Jenny"}

The previous chapters have explored the extent to which encounters with the fallen woman, insofar as they focus on her "false" or dangerous status, preclude the possibility of dialogical reciprocity. My main literary object of study has been the realist novel and the predicaments of character and form that emerge within that genre. In this chapter, I examine the depiction of fallenness in relation to a rather different literary form, the dramatic monologue. The Victorian dramatic monologue, as we shall see, holds an important relation to the concerns of this study. As a genre that displays at once the situatedness of speech and the solipsism of the individual speaker, dramatic monologue often seeks to reveal the many distortions, imbalances, and manipulations, both conscious and unconscious, that attend any speech act. Dramatic monologue invites one to analyze intersubjective relations between the lines, so to speak, and here provides the opportunity to show with particular vividness the several ways projected anxieties about agency overpower encounters with fallen women.

Dante Gabriel Rossetti's monologue "Jenny" displays multiple versions of the Victorian rhetoric of fallenness. As an unspoken address to a potential auditor who herself appears to exist in varying states of semiconsciousness throughout the poem, "Jenny" has actually been described as "the first interior monologue in English literary tradition unrecognized as such. ${ }^{\prime 1}$ I suggest, however, that

1. Daniel Harris, "D. G. Rossetti's 'Jenny'" 197. I am generally indebted to Harris's article, which challenges previous critical assumptions that the monologue 
"Jenny" is not so much an interior monologue as the negation of dramatic monologue. The "speaker" repeatedly decides not to talk to the prostitute; and I argue that his failure to speak to her emerges precisely out of the extreme intersubjective distortions that characterize encounters with the fallen. ${ }^{2}$ While actual speech is certainly no guarantee of mutual recognition, and while ordinary dramatic monologue itself explores imbalances of power, this poem heightens the failure of mutuality and reveals the anxiety over the prostitute's uncertain status by repeatedly negating the possibility of speech. Furthermore, insofar as this Victorian literary text focuses sustained attention on an actual prostitute figure (rather than consigning her to the margins, as do the works of Dickens and Gaskell), it accentuates the economic and sexual concerns that often take muted forms in other representations of fallenness. Dickens and Gaskell stress the extent to which prostitutes and fallen women figure the power of social environment and cultural forms over character; Rossetti's poem, by contrast, displays how the mutually imbricated forces of sexual desire and commodification also unsettle deliberative action, private identity, and sympathetic communication.

We saw in the reading of Mill that the Victorian investment in self-control focused not only on manipulating the circumstances that determine character but also on a more direct control over habits and temptations. As Mill states in On Liberty, "One whose desires and impulses are not his own, has no character, no more than a steam-engine has a character. ${ }^{\prime 3}$ Autonomy and control are so fundamental to human integrity, in other words, that unrestrained "desires and impulses" effectively turn one into a machine. Vice is thus rearticulated to an amoral concept of determined or nonreflective identity and, in its undermining of deliberative action, is far more threatening than intentional evil. The fullest elaboration of the threats that desire and impulse pose to self-control is to be found in Victorian psychology, which generally constructs women as more susceptible to disruptions of desire and to the forms of madness and

is spoken and provides a subtle treatment of the approach to communication in the poem.

2. To be exact, speaker should always appear in quotation marks, since of course the protagonist is actually a nonspeaker; however, for the sake of readability, from this point it appears without marks.

3. John Stuart Mill, On Liberty 264. On Liberty was originally published in 1859. 
fractured identity associated with those disruptions. Men, by contrast, are more capable of overcoming or vanquishing impulse, as evidenced succinctly in the title of an 1843 text by John Barlow: Man's Power over Himself to Prevent or Control Insanity. ${ }^{4}$

In a similar way, the idea of rational self-interest that informed Victorian political economy sought to uphold the notion that masculine agents exerted control over processes in the economic sphere, in part because there was a concomitant apprehension that such "agents" were also powerfully subject to external forces such as exchange, circulation, and commodification. In Chapter 1 , we saw a similar tension animating the philosophies of social reform, which themselves shared close ties to political economy. In Rossetti's "Jenny," which treats the visit of a scholar to a prostitute, the forces of exchange and desire are perceived to fully infiltrate experience, threatening notions of stable and recognizable identity. The complex of anxieties surrounding this disturbing perception centers on the fallen figure of the prostitute and on counterposing, and continually thwarted, ideals of agency, identity, and recognition.

Furthermore, in Rossetti's poem the notion of contamination by means of exchange extends to the aesthetic register as well and can be traced through recurrent images of reading and of books. Unlike Gaskell, Rossetti does not isolate specific cultural forms such as melodrama and romance; nor does he focus, as does Dickens, on the power of narrative over character. Rather, Rossetti's poem reveals more general anxieties about communication itself and about the instabilities of any linguistic act, whether it takes place between persons or between a person and a text. As does the rhetoric of fallenness more generally, Rossetti's poem registers a profoundly modern conception of identity and social life, in this case through an arresting conception of the textual determinants of identity. And, once again like the rhetoric of fallenness more generally, the apprehension of determined identity masks a frustrated ideal: the poem harbors the possibility of an identity and a form of interaction that would somehow exist outside of language, which is itself seen as inextricably bound up in the forces of desire and exchange. The

4. John Barlow, Man's Power over Himself to Prevent or Control Insanity. For a discussion of the gendering of madness in Victorian England, see Elaine Showalter, The Female Malady. 
prostitute, whose unsettling status traces precisely to the economic, sexual, and aesthetic determinants that haunt the speaker, provokes anxiety and suffers penalties because she constantly reminds the speaker of the illusoriness of his ideal. ${ }^{5}$

The question of whether Rossetti intends his poem as a critique of that which it so vividly displays through the speaker's meditations is a difficult one to answer-but this is always the interpretive dilemma posed by dramatic monologue, which characteristically generates moral ambiguities by eliciting both sympathy and judgment from the reader. ${ }^{6}$ In many ways the poem must be seen to reproduce the rhetoric of fallenness, especially insofar as it attempts to convey this troubling speaker as sympathetic; still, through the techniques of revelation that characterize dramatic monologue, the poem at least partly disrupts the monologic vision of the speaker, indirectly insisting on Jenny's elusiveness and indeterminacy. Such moments thwart the speaker's attempt to objectify and stabilize his apperception of her, and indirectly suggest a more open-ended dialogical ideal.

\section{Apostrophe and Agency}

The speaker of this poem does not simply refuse to talk to Jenny; he has impulses to engage her that are checked by the apprehension that she is not a conscious, possibly not even an animate, being. Thus this poem does not simply foreclose the prostitute's agency, as do other constructions of fallenness; it anxiously and recurringly disavows it. In this sense, the "nonauditor" of this poem affects the "utterance" of the speaker as the auditor affects the speaker's utterance in ordinary dramatic monologue. ${ }^{7}$ What "Jenny" distinctly foregrounds, in a manner more intense and sustained than the fic-

5. Harris similarly traces the "triangulation" of sexual, economic, and linguistic categories in the poem. However, my reading differs from Harris's in locating anxieties about agency in those categories. Harris concentrates more specifically on the issue of prostitution and on what he takes as Rossetti's indictment of "male" culture. In thinking about the way questions of agency function across different "registers" (the sexual, the economic, the aesthetic), I have found particularly useful and suggestive Mark Seltzer's "The Naturalist Machine"; see also his Bodies and Machines.

6. Robert Langbaum, The Poetry of Experience.

7. For an account of the roles played by auditors in the dramatic monologue, including their power to "resist," see Dorothy Mermin, The Audience in the Poem. 
tional portrayals I have previously analyzed, is the local intersubjective effects and maneuvers produced by the pervasive rhetoric of fallenness. The central instance in which the speaker's impulse to speak is thwarted occurs nearly halfway through the poem, when it is revealed that what precedes and what follows are unspoken thoughts:

Suppose I were to think aloud,-

What if to her all this was said?

Why, as a volume seldom read

Being opened half-way shuts again,

So might the pages of her brain

Be parted at such words, and thence

Close back upon the dusty sense.

$$
\text { (1l. 156-72) }
$$

Note the series of shifts: Jenny is posited as a potential auditor, then figured as an (inanimate) book, open only by virtue of being spoken to, and then finally reanimated, but only as book, her pages presumably closing back of their own accord. This moment, during which we become aware that the poem is unspoken, carries the force of revelation since the speaker has so conspicuously and so frequently employed Jenny's name in direct address. And the best way to view what we now recognize to have been a compensatory stream of "addresses," I suggest, is as a form of apostrophe that both reflects and counters a crisis in the perception of Jenny's status. On one level, it is true, the "directness" of repeated address seems to act as a form of recognition. But not to speak such a form of address, and to use it solipsistically in the very presence of the subject it "invokes," eerily implies that this subject exists only by virtue of being addressed by the speaker, who is thereby endowed with the power to animate. ${ }^{9}$ In conventional apostrophe, direct address func-

8. All quotations from the poem follow William M. Rossetti's edition of The Collected Works of Dante Gabriel Rossetti. Harris points out that in this passage Rossetti altered the form of the poem from its earlier drafts, in order to indicate clearly that it was an unspoken monologue. According to Harris, the poem is only explicitly indicated to be spoken in the earliest draft (1848). Drafts date from 1848, 1858, and 1869 (two). The final version appeared in Poems (1870). Harris, "D. G. Rossetti's 'Jenny'" 197-98.

9. This discussion draws on work on apostrophe by Barbara Johnson and Jonathan Culler. See Johnson, $A$ World of Difference chap. 16; Culler, The Pursuit of Signs chap. 7 . 
tions to posit the animate existence of an otherwise dead, inanimate, or absent being. Here apostrophe works to insist that "Jenny" is in need of animation. Even more: it entails an act of deanimation that renders the act of animation both necessary and potent. The speaker wards off uncertainties about Jenny's agency by appropriating the power of life and death to himself.

That the move to apostrophize entails an act of deanimation is suggested by the very manner in which the speaker inaugurates the use of direct address. The poem begins by describing Jenny in the third person and enacts a rather sudden syntactical shift to the second person in line 6:

Lazy laughing languid Jenny

Fond of a kiss and fond of a guinea,

Whose head upon my knee to-night

Rests for a while, as if grown light

With all our dances and the sound

To which the wild tunes spun you round.

The first line is ambiguous as to whether Jenny is being addressed or described, though the sequence of adjectives and the appearance of whose in line 3 make one initially infer the latter. But the syntactical turn of line 6 effectively spins the inert Jenny round and constitutes her as addressee. This turn is followed by the first explicit direct address in the poem (which I quote presently), but it is worth noting that when Jenny is here addressed in the second person she is cast in a passive, objectified role; she is not agent but patient, being spun round by an external force. If a condition of apostrophe is the addressee's absence or death or lack of animation, then perhaps it becomes crucial to see Jenny's being spun round as something more absolute than merely following a dance; rather, Jenny is spun round more in the fashion that Lucy is "rolled round" in "A Slumber Did My Spirit Seal." ${ }^{\prime 10}$

The lines that follow encourage and extend such a reading, in that they evoke two moments that frame the act of murder in Browning's

10. Not only is Jenny being "spun" round, as Lucy is "rolled round," but the first two lines of Wordsworth's second stanza also constitute an apt description of Jenny's condition in the poem: "No motion has she now, no force; / She neither hears nor sees." 
"Porphyria's Lover." In that poem, the woman addressed by the speaker is not simply dead or inert but actively rendered so. The apprehension that enacts the lover's shift from indecision to action ("That moment she was mine, mine, fair") and the uncanny reanimation of the corpse that occurs when he ceases to strangle her ("And I untightened next the tress / About her neck; her cheek once more / Blushed bright beneath her burning kiss") are both evoked in the speaker's first address to Jenny:

Fair Jenny mine, the thoughtless queen

Of kisses which the blush between

Could hardly make much daintier.

The evocation of "Porphyria's Lover" suggests an unsettling indexical function for the otherwise vaguely pejorative thoughtless: it stands in as the effect of an unrepresented act of deanimation. These correspondences, moreover, merely extend an already implicit reference to Browning's poem: the static quality of the scene in "Jenny," along with the position of the pair, reflects the pose orchestrated and then sustained throughout the night by Porphyria's murderer. The presupposition of the speaker's apostrophes-that Jenny is in need of animation-is secured through the encrypted violence of these allusive devices. And through repeated apostrophic address, the poem then works to compensate for the very conditions that it creates through its own inauguration of apostrophe.

\section{"Countless Gold Incomparable"}

In Myths of Sexuality: Representations of Women in Victorian Britain, Lynda Nead argues that the prostitute "occupies a unique place" in the economic system: "She is able to represent all the terms within capitalist production; she is the human labour, the object of exchange, and the seller at once. She stands as worker, commodity and capitalist and blurs the categories of bourgeois economics in the same way that she tests the boundaries of bourgeois morality." ${ }^{\prime 1}$ Nead goes on to say that the prostitute's ability to blur bourgeois 
categories and appropriate male economic prerogatives is the source of her threatening stature and the cause of a pervasive scapegoating. In "Jenny," the blurring of categories is extreme: indeed, the prostitute is not exactly cast as both object of exchange and economic actor; instead, she is demonstrated to be neither. This portrayal is in keeping with the negative mode of the poem and serves to heighten the anxiety about agency. To the extent that she acts, Jenny is cast as an object; to the extent that she is an object, the poem fetishizes and animates her. It is not surprising that the prostitute should serve as a heightened instance of both reification and commodity fetishism: she sells herself or, what amounts to the same thing, she sells a part of herself that is taken to be inalienable. This paradox produces a clear tension in Rossetti's poem. The imperfect end-rhyme of the first couplet (Jenny/guinea), for example, both suggests and unbalances an equation between Jenny and a piece of money. The metaphorical substitution of gold for Jenny's hair ("whose hair is countless gold incomparable") follows the more artificial form of comparison (simile) used to describe her eyes ("Whose eyes are as blue skies"), but there is a tension internal to the metaphor itself (ll. 10-11). Countless obeys the logic of the commodity, if negatively; incomparable resists that logic (since nothing, necessarily, is incomparable to the abstract form of the commodity).

The poem thus displays an uneasiness with Jenny's commodification, revealing and resisting it. However, the correlations between Jenny and the object of exchange function not only to display commodity fetishism but also to shore up the poem's systematic disavowal of Jenny's status as an economic agent. This foreclosure of Jenny's agency is motivated, my reading suggests, not so much by the prostitute's appropriation of male economic prerogatives as by the speaker's investment in an ideal purity free from the realm of desire, exchange, and, ultimately, the instabilities of communication. Crucially relevant here is the speaker's anxiety about the nature of his own aesthetic "work."

In the "child's tale" describing the prostitute's rise and fall, Jenny is subjected to the kind of conventional narrative containment we have seen before: the "tale" serves as a condensed version of the way narrative constitutes subjectivity. Not only is Jenny fully assimilated to a narrative of which she is a mere instance, but she is indicated, to the extent that she acts, only metonymically: her "lifted silken skirt / Advertise[s] dainties" and her "coach-wheels splash 
rebuke/ On virtue" (11. 145-49). Metonymical figuration here actually serves double duty: it registers Jenny's wealth, figuring that wealth as productive of movement and activity, yet it also eclipses Jenny as agent. Only when wealth and health are irretrievable does the prostitute appear to project-as vision-her subjectivity, but then she immovably stares "along the streets alone," incapable of responding to, or even apprehending, the children who thus identify her (ll. 149-50). The prostitute's stare is only an allusion to subjectivity and is analogous to the pathos of amnesiacs, whose eyes seem to project a saddened awareness they are incapable of feeling. An image of redemption does appear, it is true-the "fiery serpent" of Numbers 21: 8-9. But whereas in Numbers, the act of beholding the brass serpent effects redemption, this serpent is significantly beyond the range of Jenny's vision, "round the long park, across the bridge" (l. 151). ${ }^{12}$ The hiatus between the prostitute's stare and a redemptive act of beholding is then duplicated in the lines that follow. The speaker justifies his silence by describing Jenny's "desecrated mind" as utterly unable to comprehend the (potentially redeeming?) narrative he has just recited.

At the only moment in the poem when Jenny might perform a discrete, motivated action, her threatening economic status is again registered and counteracted. The speaker appears to be handing her a glass of wine:

But that the weariness may pass

And leave you merry, take this glass.

Ah! lazy lily hand, more bless'd

If ne'er in rings it had been dress'd

Nor ever by a glove conceal'd!

Behold the lilies of the field,

They toil not neither do they spin.

(11. 95-101)

It seems that some kind of overt gesture, if not explicit utterance, is made by the speaker here. However, the apprehension of Jenny's

12. "And the Lord said unto Moses, Make thee a fiery serpent, and set it upon a pole; and it shall come to pass, that every one that is bitten, when he looketh upon it, shall live.

"And Moses made a serpent of brass, and put it upon a pole, and it came to pass, that if a serpent had bitten any man, when he beheld the serpent of brass, he lived." Numbers 21: 8, King James version. 
hand as disinclined to action and the (not uncharacteristic) rapidity with which the speaker becomes distracted might act rather to forestall any actual attempt to hand Jenny the glass. The "Ah!" followed directly by "lazy" suggests that here the speaker is experiencing the inert hand as a check to his advance. This positing of inherent nonactivity is then extended in the evocation of the lilies of the field. Jenny's wealth is registered again indexically, in the "rings" and "gloves," and cast, at least in relation to the glove, as deceptive, concealing. If to be dressed is to be concealed, as the alignment of the two words implies, the "lazy lily hand" synecdochally suggests that the "real" Jenny is Jenny's body. Recall too that lazy is the first word used to describe Jenny and the first word of the poem. Yet, as we saw earlier, activity adheres not in that body but in the commodities that attach, deceptively, to it. The speaker's strategy is thus to (literally) divest Jenny of the power of agency, revealing her as incommensurable with a projected wealth.

It is interesting to view Jenny's threatening appearance of wealth in light of the description of the virtuous working girl. Jenny is allegedly glad to evade "the pale girl's dumb rebuke, / Whose illclad grace and toil-worn look / Proclaim the strength that keeps her weak" (1l. 73-75). Like Jenny, the working girl is dumb, but her virtuous identity proclaims itself and is immediately legibleher "look" does not deceive or conceal, her grace is not covered over but "ill-clad." This passage clarifies the anxiety that Jenny's (otherwise "mere") appearance of wealth can induce: the appearance also conceals and, like her silence, renders her disturbingly illegible.

Toward the end of the poem, the speaker projects Jenny's dream and then interprets it as a desire for recognition through luxury and dress. Jenny is curiously absent from the dream itself; more precisely, she constitutes the absent center of an environment characterized by constant motion and animate force:

Or like a palpitating star

Thrilled into song, the opera-night

Breathes faint in the quick pulse of light;

Or at the carriage window shine

Rich wares for choice; or, free to dine, Whirls through its hour of health (divine For her) the concourse of the Park.

(ll. 352-58) 
It is not Jenny who "breathes faint" or "whirls" or is "thrilled." No center of motion or experience herself, the dreamer merely produces images associated with wealth. That the only indication of her own satisfaction as well as her possible presence within the dream itself is interpolated parenthetically merely reinforces Jenny's exclusion from the surrounding syntax, which itself thwarts any actual insertion of the dreaming subject into the coveted context. The speaker's interpretation of Jenny's dream-that it gives her a satisfying sense of distinction-is thus undercut by his representation of the dreaming itself. It is hard to see how this dream constitutes Jenny as "the acknowledged belle / apparelled beyond parallel" (ll. 362-64), since there doesn't seem to be any actual scene of recognition in the dream itself.

To the extent that the poem does resist commodifying Jenny, it casts her as essentially nonquantifiable but not as an acting, conscious subject. That is, Jenny's essence can be protected or appealed to, but her consciousness cannot. Moreover, the nature of the essence itself furnishes the explanation for the denial of economic agency. The act that Jenny would perform, in economic terms, is that of selling, but the product that she sells is, for the speaker, an original purity that not only constitutes her ideal identity but also remains definitively inaccessible to any economic or sexual contaminations: as such, it cannot be given any communicative form and must remain ineffable and unread. Purity, in the poem, is thereby accorded the status of pure anteriority or pure otherness. It is no accident that in the figural sequence directly following the phrase "countless gold incomparable" a temporal predicament is played out:

Fresh flower, scarce touched with signs that tell

Of Love's exuberant hotbed:-Nay,

Poor flower left torn since yesterday

Until tomorrow leave you bare;

Poor handful of bright spring-water

Flung in the whirlpool's shrieking face.

(11. 12-17)

As a fresh flower, Jenny is already "touched with signs that tell" of impurity: this image necessitates a revision that evokes a more explicit notion of original purity. As a flower "left torn" since yester- 
day, Jenny is poised between purity and corruption, poignantly at the mercy of time. The third figure extends the implication of an identity that is purely anterior: the "handful of bright spring-water" is substantially equivalent to, and effectively absorbed by, a malign environment that now, in its "shrieking face," grotesquely mocks subjectivity. The loss of purity is the loss of identity.

Jenny's purity is also cast as pure anteriority just previous to the "child's tale," whose point of origin postdates the fall. Her pastoral innocence, "When she would lie in fields and look / Along the ground through the blown grass," constitutes a pre-narrative: "the old days which seem to be / Much older than any history / That is written in any book" (ll. 127-31). Fundamentally incommunicable, allowed no textual instantiation, purity for the speaker remains outside narrative and hence cannot be passed along through textual interchanges. But the word seem is crucial here: purity or identity is constituted after the fact, in the manner of an après-coup, accessible only through memory. The predicament of fallenness as inescapably public identity simply cannot be eluded, as is again displayed toward the end of the poem when the speaker showers golden coins in Jenny's hair. What has been posing a profound threat, and what in one sense constitutes the fall, is the possibility of giving original identity an exchange value, but here the speaker himself undergoes this transformation. When he translates himself into coin, in the hope of being distinctly remembered, he dooms his desire, for he loses all individual identity in leaving the coins.

Precisely because purity is constituted as inaccessibly anterior or definitively nonembodied, distinctions between Jenny and the speaker collapse. The extreme investment in private and protected identity here reveals its delusions, as the condition of the prostitute thus cannot help but be the condition of all. In the period in which Rossetti was writing, there was profound anxiety not only about women taking their private bodily wares to market but also about the market-oriented forms that ostensibly private intellectual and aesthetic practices were taking. The rise of serial publication and the professionalization of writing invited comparison between authors and prostitutes: a man's text, like a woman's sex, was seen as something that one should not parcel out for pay. ${ }^{13}$ The fact that the 
speaker refers to his "work" only once, and then only in relation to the elusive activity of "reading," reinforces the possibility that he wishes to think of his own intellectual and aesthetic practices in distinctly noneconomic terms. Jenny thus can be seen to function as a double for the speaker, who himself never succeeds in fully disavowing the extent to which his identity, both as a scholar and as Jenny's client, is bound up in networks of exchange.

\section{Dormant Desires}

As the above discussion of purity suggests, the question of whether or to what extent Jenny is a conscious being emerges in sexual as well as economic terms. To discuss the sexual register, then, requires a certain double awareness: in general the anxiety deriving from Jenny's vexed economic status cannot be separated from anxieties about sexual desire. Indeed, the economic and the sexual categories are blurred in the poem's opening verse paragraph, first when Jenny is described as "Fond of a kiss and fond of a guinea," and then some lines later, when the speaker wonders, "Whose person or whose purse may be / The lodestar of your reverie?" (11. 2, 20-21). The shift from and (in the first pairing) to or might be said to enact and perhaps prefigure a shift from a logic of mutual implication to one of mutual exclusion, but the phonetic nearequivalence of person and purse seems to suggest an identity underlying, or inhabiting, the opposition. What this complex of formulae indicates is that the relation between the sexual and economic remains fluid in the poem, and one category cannot be said to take precedence over the other, nor are they equated with one another in any simple way.

On one level, the relation between the speaker and Jenny, and in particular their pose, emblematize the unequal balance of desire that attends an act of prostitution. But the relation between the two also represents a conception of sexual difference that was current during the years Rossetti worked on the poem, particularly in reformist accounts of prostitution by writers such as Greg and Acton. ${ }^{14}$ This

connections between feminine purity and an ideal of literary labor as safe from the contaminations of the market, see Mary Poovey, Uneven Developments 89-125.

14. See [W. R. Greg], "Prostitution"; William Acton, Prostitution Considered in Its 
view stressed feminine sexual passivity, claiming that women were devoid of sexual appetite or, alternately, unconscious of any desire until it was excited by the sexual initiations of men. Male lust, on the other hand, was primary and active. Though by no means the only or indisputably "official" view of sexual difference in the period, it did prove especially useful to reformers who sought to absolve prostitutes of responsibility for their fall and to deny any inherent corruption on their part. ${ }^{15}$ As we saw in the previous chapter, Gaskell's vindication of Ruth draws directly from this general view of sexual difference and from Greg more specifically.

The theory of sexual passivity allowed for an (at least locally) enabling confusion between feminine sexual purity and feminine sexual corruption. Greg, for example, argues that "a vast proportion" of kept mistresses who later became street prostitutes "fell in the first instance from a mere exaggeration and perversion of one of the best qualities of a woman's heart":

There is in the warm fond heart of a woman a strange and sublime unselfishness, which men too commonly discover only to profit by,-a positive love of self-sacrifice,-an active, so to speak, an aggressive desire to show their affection, by giving up to those who have won it something they hold very dear.... This is no romantic or over-coloured picture; those who deem it so have not known the better portion of the sex, or do not deserve to have known them. ${ }^{16}$

This passage, which Acton cites approvingly, essentially argues that many fall because of virtue; more important, like those Victorian domestic ideologues who stressed the potency of selfless activity, Greg grants to women a compensatory, magnified activity (if nonetheless qualified by a "so to speak") only insofar as it is the index

Moral, Social, and Sanitary Aspects. Also see Chapter 1 for a related discussion of Greg, Acton, and other writers on prostitution.

15. F. Barry Smith argues that Acton, who has often been taken as representative of the official Victorian view of sexual difference, is not only not representative but was actively refuted by many contemporaries. See Smith, "Sexuality in Britain, 18001900." It is certainly true that a more active, threatening form of female sexuality was registered in contemporary psychology. For the purposes of my reading, it does seem significant, however, that the rather extreme and counter-intuitive theory of "sexual anaesthesia" crops up in writers specifically concerned with prostitution.

16. Greg, "Prostitution" 459. 
of a self-denying instinct, only insofar as they are precluded from being sexual agents in their own right.

Ultimately, however, the figure of the passive woman displaces a predicament of agency that attends not merely feminine desire but desire in general. This displacement occurs both in Greg and in Rossetti, and in both instances it destabilizes what appears to be a founding distinction between masculine and feminine desire. Take, for example, the following passage from Greg's article:

Women's desires scarcely ever lead to their fall; for (save in a class of whom we shall speak presently) the desire scarcely exists in a definite and conscious form, till they have fallen. In this point there is a radical and essential difference between the sexes: the arrangements of nature and customs of society would be even more unequal than they are, were it not so. In men, in general, the sexual desire is inherent and spontaneous, and belongs to the condition of puberty. In the other sex, the desire is dormant, if not non-existent, till excited; always till excited by undue familiarities; almost always till excited by actual intercourse. Those feelings which coarse and licentious minds are so ready to attribute to girls, are almost invariably consequences. ${ }^{17}$

The "radical and essential difference between the sexes" is here marked by an asymmetry: female desire is "unconscious" and "dormant" while male desire is "inherent and spontaneous." The emergence of female desire depends on an external stimulus; until then, it is unconscious. Male desire does not depend on an external stimulus; but it is not exactly conscious, it is spontaneous. The word has an odd double meaning: it denotes the voluntary as well as the impulsive. A man may have an active sexuality but it is not clear that he has a controlled one; his agency is protected, but not his capacity to, as Mill puts it, "make [his] desires and impulses ... his own." The issue of consciousness in or of desire is thus unresolved in the case of the man; this irresolution is partly masked by the fact that the woman is more emphatically defined against the possibility of conscious desire, even if time and events can alter her condition.

Distinctions between purity and fallenness, and between masculine and feminine desire, are similarly dislodged in Rossetti's poem, in which the speaker fears, not exactly becoming a steam

17. Greg, "Prostitution" 456-57. 
engine, but in any event a too-close identification with the spinning Jenny. As in Greg, the ostensibly more stable opposition is between masculine and feminine desire, and the upsetting of the distinction between pure and fallen seems a more studied, achieved effect, an attempt at partial vindication. This instability between fallenness and conventional purity, however, does not contradict my earlier interpretation of purity as absolute otherness; quite the contrary, for in these inscriptions of gender, the status of purity is protected only to the extent that it is never given present instantiation. Once given a form, as in the case of cousin Nell, it will inevitably devolve, of itself, into fallenness.

The identification between the "fallen" Jenny and the "pure" Nell is effected largely through resonances in the economic register. Initially, what produces the speaker's bewilderment in comparing the two women is that the pure and the fallen can, in sleep, appear to be substantially the same (1l. 177-84). The ensuing description of Nell, which seems to delimit an entirely different character and destiny, also, mainly through echoes and puns, suggests an underlying equivalence: "My cousin Nell is fond of fun, / And fond of dress, and change, and praise" (ll. 185-86). The pun on change brings this phrase into alignment with its counterpart, "fond of a guinea." Later, change and dear function doubly, reinforcing this effect and essentially casting marriage as a form of prostitution: "The love of change, in cousin Nell / Shall find the best and hold it dear." The counterpart to "fond of a kiss" also appears: cousin Nell is "fond of love." What seems to set Nell apart from Jenny most centrally is, to borrow Greg's terms, her "sublime unselfishness": "The unconquered mirth turn quieter / Not through her own, through others' woe." However, the proliferation of the word fond, and of the objects it takes, seems to transform its meaning from mere affection into restless, if muted, desire.

In his more explicitly polemical or philosophical moments, the speaker continues to naturalize gender identity, accounting for Jenny, and for prostitution in general, by citing the primacy and violence of male lust. An entire verse paragraph, distinguished by a highly impersonal tone, is devoted to a description of lust as "a toad within a stone / Seated while Time crumbles on"(1l. 282-83). That the referent in this paragraph is not humankind but men in general is supported by the speaker's earlier assertion that Jennysilent, inactive-is most powerfully victimized by the "hatefulness 
of man," "whose acts areill and his speech ill" (ll. 83, 85). The static, transhistorical account is reproduced in the relation between the voluble speaker and the inert, "dormant" Jenny. But even though we are far from the sociological reformist perspective here, the account of gender difference and desire is not entirely stable. The nature of its instability is displayed most tellingly in the functioning of the figure of the book, a figure that ultimately links the issues of sexual desire, uncertain agency, and intersubjective recognition.

The book in Rossetti's poem acts as a device that mediates between the activity of reading and the apprehension of concrete subjects in the world. For this speaker not only experiences threats to identity in economic and sexual exchange but also fears the instabilities of any communicative exchange, which he associates with the undecidability of reading in general. However, to the extent that the concrete delimited entity of the book-and not sheer language or text-figures the concrete other, the potentially precarious activity of reading and even distinguishing the other can be stabilized. Moreover, in this poem desire emerges from, and is in part a response to, a breakdown in the reading of actual texts. Hence, the figuring of people as books serves to indicate and, again, stabilize a distinctly eroticized unreadability. For the speaker, in other words, the figuring of people as books tames the textuality of otherness as well as figures the eroticization of reading. We know that the speaker's visit to the prostitute is occasioned by a certain breakdown of the (literal) reading process. He describes the "cloud" that made his brain "turn and swim / While hour by hour the books grew dim" (ll. 44-45). In explaining how he came to meet Jenny, he at once describes and displays the emergence of cognitive destabilization:

... I vowed that since my brain

And eyes of dancing seemed so fain,

My feet should have some dancing too:-

And thus it was I met with you.

Well, I suppose 'twas hard to part,

For here I am.

Metonymical association supplants motive (figural dancing evokes literal dancing); the stop-and-start quality of the lines seems to expose meaning as a tautological process of positing. But to describe 
this experience merely as a "breakdown" is to cloud over the erotic play signified by "dancing." As the site of the emergence of the erotic, the breakdown of readability is not an unpleasurable predicament.

This account of the emergence or structure of desire must be viewed against the eroticized apprehension of Jenny as book. On one level, the latter certainly evokes associations between pornography and prostitution and obliquely alludes to the attitude of censorship that the poem defies. ${ }^{18}$ But, in terms of the argument I am sketching, what is more important is the way it works to deanimate and reify Jenny as well as, ultimately, to subvert the distinction between her and the speaker:

Why, Jenny, as I watch you there,For all your wealth of loosened hair, Your silk ungirdled and unlac'd And warm sweets open to the waist, All golden in the lamplight's gleam,You know not what a book you seem, Half-read by lightning in a dream! How should you know, my Jenny? Nay, And I should be ashamed to say:Poor beauty, so well worth a kiss!

But while my thought runs on like this With wasteful whims more than enough, I wonder what you're thinking of.

If of myself you think at all, What is the thought?-conjectural On sorry matters best unsolved?Or inly is each grace revolved To fit me with a lure?(11. 46-63)

Part of the strangeness in the first lines of this passage derives from an ambiguity surrounding the intensity of the speaker's response: is his experience of satisfaction occasioned by Jenny's deshabille or by his perception, or rather hallucination, of her as book? These two

18. For a discussion of the relation between Rossetti's poem and pornography, see Robin Sheets, "Pornography and Art." 
things do not appear to be mutually reinforcing. It is true that a highly eroticized Jenny evokes reading, and this association is mediated by the figure of the book. But this mediating figure is also what prevents a real erotic exchange between Jenny and the speaker, since on one level the book is defined against erotic accessibility: Jenny is a book despite ("for all") her inviting accessibility. Here one might also recall, in particular, the "serried ranks" the speaker left behind in his room as he went in search of "real" dancing. The telos of the erotic impulse, which in this poem originates with an act of reading, is an intersubjective encounter, yet here the inability not to see Jenny as a book throws the speaker back into himself.

As soon as Jenny is seen as a book, in fact, the speaker becomes languid and self-incriminating. And what the speaker is "ashamed" of here seems to be the lapse into the masturbatory mode, which, for the Victorians, was associated with excessive reading. ${ }^{19}$ In the ideology of the period, masturbation was seen as a useless and depletionary expenditure, one that led ultimately to impotence. As Steven Marcus points out, semen was seen along the model of money in an economy of scarcity. ${ }^{20}$ The sequence here seems not insignificant: the woman is figured as a book; the speaker characterizes his thoughts as running on with "wasteful whims more than enough"; lodged between is the lament, "Poor beauty, so well worth a kiss" - not accompaniment to a kiss but apology for his own autoerotic mode.

The speaker then wonders at Jenny's thoughts, and his first projection as to their drift alludes, one might assume, to the question of his sexual potency ("sorry matters best unsolved"). The second projection evokes the question of the extent to which Jenny designs or consciously seduces: "Or inly is each grace revolved / To fit me with a lure?" Jenny's uncertain status here carries a new edge to it:

19. Similarly, at least one commentator on prostitution saw scholars as particularly susceptible: "Literature, like wealth, is inadequate to secure its possessor against the consequences of prostitution. Perhaps the baneful effects of licentiousness are not more painfully exemplified in any class of citizens, than among those who pursue the paths of literature and science. In order to relieve the dull hours of study, they resort for recreation to the tavern and brothel, till the habit becomes inveterate and irresistable." Ironically, however, he later suggests that reading will serve to diminish sexual excesses among servants: "Let a habit of reading, instead of a habit of drinking, be introduced and encouraged amongst household servants, and a different state of things will soon appear." William Tait, Magdalenism 184, 213.

20. See Steven Marcus, The Other Victorians 12-25. 
the speaker imagines her as poised midway between design and action. Jenny's inertness becomes the very index for agency, since it casts her as the embodiment of pure deliberation, the threshold of action. Moreover, if you hear "a lure" also as "allure," then the apprehension of Jenny's latent agency is conflated with the possibility that the speaker cannot answer her desire: she is revolving his graces in an attempt to fit him with "allure." Here feminine desire threateningly exceeds, rather than is subordinated to, masculine desire. This moment of empowerment-and it is but a moment, for the speaker moves on to cast his own activity as a form of benefaction-seems to be prompted by the evocation of the "sorry matters best unsolved." But it would be inaccurate to say that this "reversal" reveals that Jenny is truly potent while the speaker is impotent; rather, it is one among several moments in the poem showing that desire severely attenuates one's pretension to agency. To cede or to deny agency to Jenny, depending on its context, can be an attempt, on the speaker's part, to ward off the instabilities of desire itself.

\section{"Like a Rose Shut in a Book"}

To follow the vicissitudes of the figure of the book is to gain some insight into Rossetti's conception of the possible forms of intersubjective experience. The interventions performed by this figure work generally, though never manage fully, to stabilize perceptions of the other as well as to foreclose mutual perception or dialogical intercourse.

There are two "closed" books in the poem, both of which function as images for Jenny. In one instance, which I have already discussed, the figure of the book emerges as the speaker contemplates the effects his words would have if spoken aloud. What is explicitly at issue here is the possibility of a spoken exchange; this is moreover the moment at which the form of the poem, as the negation of dramatic monologue, is revealed:

Suppose I were to think aloud,-

What if to her all this were said?

Why, as a volume seldom read

Being opened half-way shuts again,

So might the pages of her brain 
Be parted at such words, and thence

Close back upon the dusty sense.

For is there hue or shape defin'd

In Jenny's desecrated mind,

Where all contagious currents meet,

A Lethe of the middle street?

Nay, it reflects not any face,

Nor sound is in its sluggish pace,

But as they coil those eddies clot,

And night and day remember not.

Why, Jenny, you're asleep at last!

(ll. 156-71)

An objectified model of reading eclipses the possibility for dialogue and conditions the encounter. Jenny, like the book, is brought alive, and made legible, only through the consciousness of the speaker; apart from that, she is not nonexistent, but rather the embodiment of uninterpretability, utter confusion, meaningless marks (with no "hue or shape defin'd"). The effect of being read will not extend beyond the phase of reading-Jenny will not be altered by the activity of the speaker's consciousness as (speaking) reader. She has no memory; her mind "reflects not any face," that is, she herself projects no face, nor can she recognize the face of the other. Thus she herself cannot distinguish any intersubjective encounter within the meaningless flux.

The only possible mode of consciousness for the speaker is that of a distinctly monological reading; other subjects exist only insofar as they are read. And yet here the reading process suffers disruptions: the figure of the book does not quite succeed in managing what for the speaker remains to some extent an inaccessible, resistant, unreadable subjectivity. If Jenny is a closed book, open only by virtue of the speaker's words, she is also perceived to close herself. Note the shift from passive (if he spoke, her pages would be parted) to active (they then "close back upon the dusty sense"). As an animate book, then, Jenny cannot be in any simple way inscribed or delimited or read, though the speaker repeatedly tries to do so. The threat that she poses on this count is dramatically registered by the fact that what immediately follows is the most intense vilification of Jenny in the poem, and then the dispelling of any doubt as to 
whether she sleeps. ${ }^{21}$ The imagery employed in the vilification, moreover, retroactively refigures the motion of resistance, the closing back, as a movement of waters in upon themselves: it rewrites Jenny's hypothetical action as the mere motion of the elements.

There are other moments in which Jenny's non-response seems active, producing a kind of refutation effect against the many disavowals of her agency. These refutations tend to occur precisely at those moments when the speaker is providing universal justifications for prostitution, as for example in the passage that culminates by indicting the "hatefulness of man." The speaker's thoughts here produce his impulse to move out of reflection on prostitution and into its physical act. One might see Jenny's failure to rise to the occasion, then, as that which forces the self-interrogation to continue; she is of course not resisting the precise nature of the speaker's account, but her perceived noncompliance after his "sympathetic" account of her victimization has the effect of refutation. These are moments when Rossetti seems to encourage us to see through the speaker's superficiality as well as his defensive maneuvers. A similar effect is produced after the toad-within-a-stone account. Many point to this passage as the record of Rossetti's view on prostitution, without paying attention to the lines that follow. Again, the speaker moves to engage Jenny ("Jenny, wake up..."), yet he is then immediately distracted by the apprehension of dawn and an evocation of the market. The noise associated with the move toward the marketplace (the "bleating" sheep and "barking dog") breaks the hermetic silence of the speaker's discourse and, like the later ring of the coins, speaks the economic realities underlying his mystified meditations (1l. 303-6).

The other occurrence of the figure of the closed book centers on its contaminating power, a quality that also appeared in the description of Jenny as a self-shutting book: there her mind is a place "where all contagious currents meet, / A Lethe of the middle street." Here Jenny, as representative fallen woman, is cast as a "rose shut in a

21. It has been argued (Harris), as well as assumed (Auerbach), that Jenny sleeps throughout the poem. Harris argues that, in line with the conventions of dramatic monologue, the speaker's self-absorption is signaled in his inability to properly perceive Jenny's sleep. However, the uncertainty of Jenny's state, the difficulty in distinguishing rest from sleep in the other, is a crucial aspect of the problems in agency that the poem displays. And of course this moment of perceiving that Jenny finally sleeps-i.e., is really unconscious-is importantly placed. See Harris, "D. G. Rossetti's 'Jenny' " 202 n. 7, and Nina Auerbach, Woman and the Demon 155. 
book": the rose represents the crushed "flower within the soul"; the book, at least initially, is the corrupting medium. As in the previous instance, the intersubjective scenario is important: the speaker is lamenting that an act of ideal reading - of the fallen by the pureis necessarily impossible:

If but a woman's heart might see

Such erring heart unerringly

For once! But that can never be.

Like a rose shut in a book

In which pure women may not look,

For its base pages claim control

To crush the flower within the soul;

Where through each dead rose-leaf that clings,

Pale as transparent psyche-wings,

To the vile text, are traced such things

As might make lady's cheek indeed

More than a living rose to read;

So nought save foolish foulness may

Watch with hard eyes the sure decay.

(11. 250-63)

It becomes impossible to read directly (from the heart, to the heart, as the speaker conceives it) because the rose clings to the page, thereby becoming, from one perspective, imprinted - "traced"- by the contaminating or "vile" text. But one can also read the pure woman rather than the impersonal text as the agent who traces. In this act of reading, however, it is as though the text supplants the rose as object of the pure woman's consciousness. The placement of the phrase "to the vile text" invites such a reading: less that the rose leaf "clings" to the vile text than that the blush-inducing images are, by the woman, traced to it. These lines further suggest the possibility that the rose, despite its near-transparency, is itself the corrupting medium, that which colors and makes necessarily "erring" the act of reading: the woman traces the vile text "through each dead rose-leaf." Moreover, some lines later, the rose produces a "sanguine stain" (1. 270), which contradicts its earlier paleness. The preserved rose, as emblem of the now irretrievable purity, is corruption itself.

It is perhaps no accident that the corrupting of the rose occurs 
simultaneously with the possibility that, in reading the text instead of the rose, the pure woman is evincing a desire that she shouldn't have. The ambiguity of "More than a living rose to read" participates in this conflation: it is uncertain whether the woman's blush issues out of her act of reading or is at that moment being read. It becomes impossible to apprehend the pure woman as reader without reading her as compromised. Here, it is reading itself that corrupts, and the pure woman is defined against such a possibility only through the defensive gesture of prohibition.

In one sense the speaker is defining an ideal encounter even as he disallows it. This passage reveals the speaker's frustrated sense of the impossibility of any kind of direct perception: any apperception of the other also becomes an act of reading that forecloses the redemptive comprehension of an original purity. It is symptomatic, then, that the entire verse paragraph begins with an untethered simile: we never know exactly what is "like a rose shut in a book." The (fallen) woman here becomes the scapegoated figure for Rossetti's fear that the "contaminations" of an erotic textuality will always upset a posited ideal human encounter-the "unerring" reading of one heart by another. Like Gaskell, then, Rossetti opposes an idealized form of intersubjectivity to his many versions of fallenness.

There is another moment in which an idealized intersubjective structure is posited and thwarted; it is also the moment when the speaker most fully reveals himself to be subject to the problems in identity that he has projected onto Jenny. This moment occurs when he performs the spectacular and compensatory act of laying golden coins in her hair, in a blatant conflation of financial and sexual potency. ${ }^{22}$ What is clearly at stake here, for the speaker, is the need not merely to project his power but also, as we saw earlier, to con-

22. Steven Marcus describes the way Victorian pornography compensated for the economy-of-scarcity ideology surrounding male ejaculation: "The model on which the notion of semen is formed is clearly that of money. ... Furthermore, the economy envisaged in this idea is based on scarcity and has as its aim the accumulation of its own product. And the fantasy of pornography... is this idea's complement, for the world of pornography is a world of plenty. In it all men are infinitely rich in substance, all men are limitlessly endowed with that universal fluid currency which can be spent without loss. Just as in the myth Zeus descends upon Danae in a shower of gold, so in pornography the world is bathed, floated, flooded, inundated in this magical produce of the body. No one need ever worry again about husbanding nature's riches from expense." Marcus, The Other Victorians 22. 
stitute himself as a distinct and above all recognizable being. He attempts to ensure the latter by imagining that he meets Jenny's dreams in leaving the gold. Jenny dreams images of wealth; the speaker leaves her what constitutes both the representation as well as the material of wealth. But the speaker wants the gold to represent him, and he believes that this disembodied erotic nonencounter, this signature in coin, will somehow render him distinct, constituting him as the sole memory in the Lethe that is her mind.

As I mentioned earlier, the logic is faulty, since the selfobjectification into a medium of exchange renders identity indistinct. As the abstract representation of wealth, he might be meeting in a pure, unmediated way what he perceives as Jenny's desire, but he himself loses all specificity. Moreover, there is lodged in the speaker's logic a metonymical slide (from semen to self) that ensures the metaphorical substitution of gold for self. In a striking final reversal, Jenny becomes the desiring subject and the speaker is evacuated, leaving only a token of himself. He has thus become what he earlier names Jenny as being, "a cipher of man's changeless sum / Of lust" (11. 278-79). What haunts the entire passage, and ultimately the poem itself, is a thwarted desire for recognition. The structure that governs apostrophe is reversed: now it is Jenny who must animate the speaker. ${ }^{23}$

In general terms, then, "Jenny" is a poem about uncertain agency, thwarted recognition, and the profound unreadability of otherness. To center such concerns on the figure of the prostitute at once heightens and deflects the anxieties that attend these epistemological and intersubjective predicaments. For in the case of the Victorian prostitute, the problems in readability that attend the intersubjective moment are part of a complex configuration; as this chapter is designed to show, these problems are inextricably linked to economic and sexual anxieties about agency. The speaker's metonymic association of the prostitute with false representations is a means of disavowing her economic agency; this act is in turn predicated on an investment in an essential identity uncontaminated by (any kind of) exchange. This speaker fears indeterminacy as much as determinacy, however, and hence also uses the prostitute to disavow the

23. Barbara Johnson discusses a similar apostrophic reversal in Shelley's "Ode to the West Wind." Johnson, A World of Difference 188. 
fact that representations as well as other people are not as fixed and legible as the stained page that figures a lost purity. As we have seen throughout this book, the Victorian prostitute is closely identified with representation and ornamentation-with "paint," finery, narrative, melodrama, stories, and, in this case, books. "Jenny" dramatizes with extraordinary power that such associations both correspond to and enable the Victorian prostitute's multiple functions as synecdoche and scapegoat for anxieties about agency and selfhood.

Yet, as I suggested at the beginning of this chapter, we can read the poem also as a partial critique of the rhetoric of fallenness and in particular that rhetoric's tendency to thwart mutuality and recognition. Indeed, the form of the poem-its allusion to the dramatic monologue that Jenny's "figurality" renders impossible-critically inflects and frames the scenes of thwarted recognition in the poem, the laying of the golden coins as well as the rose shut in a book. These two passages reveal an objectifying stance toward self or other both in their initial idealizing impulse and in their eventual collapses into misrecognition (in the rose-shut-in-a-book passage) and nonspecificity (in the laying of the golden coins). However, not only within these very passages but also at other moments in the poem, such moves to fix the other are unbalanced by reversals that locate agency in Jenny or the woman, moments when a certain desire or resistance is perceived, registered, or located in the other. The form of the poem, which constitutes an insistence on a continuous intersubjective context, shows how the presence or fact of another consciousness not only produces moves to stabilize or foreclose the other but also continually unsettles such moves. Jenny's undecidable agency thus can assume a positive dimension, evoking the openendedness of intersubjective experience and the continuous appeal of the other. 